\title{
Risk of Transverse Myelitis Following Dengue Infection: A Systematic Review of the Literature
}

\author{
Nafisa Badat ${ }^{1}$, Dalia Abdulhussein ${ }^{1}$, Peter Oligbu ${ }^{2}$, Olakunle Ojubolamo ${ }^{3}$ and \\ Godwin Oligbu $4, *$ (D) \\ 1 School of Medicine, Imperial College London, London SW7 2AZ, UK; nafisa.badat13@imperial.ac.uk (N.B.); \\ da1813@ic.ac.uk (D.A.) \\ 2 Department of Family Medicine, University of Benin Teaching Hospital (UBTH), Benin City, Nigeria; \\ petolis2008@gmail.com \\ 3 Department of Medicine, Queen's Hospital, Romford RM7 0AG, UK; olakunle.ojubolamo1@nhs.net \\ 4 Paediatric Infectious Diseases Research Group, Institute for Infection and Immunity, St. George's, \\ University of London, London SW17 0RE, UK \\ * Correspondence: godwin.oligbu@nhs.net
}

Received: 17 November 2018; Accepted: 19 December 2018; Published: 23 December 2018

\begin{abstract}
Introduction: Dengue virus (DENV) is one of the most common arbovirus diseases, with a wide spectrum of presentation. Spinal cord involvement in dengue infection (DF) is rare. However, the risk of transverse myelitis (TM) following Dengue has not been systematically assessed. Methods: We undertook a systematic review of published English literature from January 1974 to December 2017 to assess risk of TM and outcomes following DF. Data sources included EMBASE, MEDLINE, Cochrane library, ISI web of knowledge, conference proceedings and references within identified articles. Results: We identified 242 potential studies, 62 were duplicates. A further 136 were excluded on the basis of title and abstract and 19 studies did not meet the eligibility criteria on full text screening. We included 25 publications involving 2672 cases of DF. A small proportion $(10.8 \%,(289 / 2672))$ had neurological complications, of which $2.3 \%(61 / 2672)$ was TM. For articles reporting epidemiological data, the neurological complication was twice in males compared to female $67.7 \%(130 / 192)$ vs. $32.7 \%(62 / 192)$ and 1.5 -fold increase TM for males 59.3\% (32/54) vs $40.7 \%(22 / 54)$. The mean age at presentation was 33.1years (range $0.75-61$ ), with onset at 11.7 days. The method of diagnosing TM due to DF was mainly IgM seropositivity $92 \%(n=23 / 25)$ and the commonest treatment modality was steroid $78.3 \%(\mathrm{n}=18 / 23)$. Only half had full recovery $50.8 \%$ $(\mathrm{n}=31 / 61)$. There was no mortality following dengue, however, the crude case fatality rate following TM was 3.3\% $(n=2 / 61)$. Conclusion: This review highlights the risk of TM following dengue. Although neurological complications are rare, especially TM, once set in, it is associated with a significant morbidity.
\end{abstract}

Keywords: Dengue Fever; transverse myelitis; risk; systematic review

\section{Introduction}

Dengue is a viral disease transmitted by the Aedes mosquito and is endemic in tropical and subtropical areas, in particular the Americas and Asia. This puts an estimated 4 billion people at risk of acquiring the virus; currently it is estimated 100 million cases of symptomatic dengue occur annually [1]. Lack of treatment and immunisation therapy, as well as inadequate vector control have meant that there are no options in the management of severe disease apart from supportive measures [1,2]. In addition, with population growth and increased intercontinental travel over the past decade, it is more likely, if no other combative measures are utilised, that the number of cases will continue to increase. 
The vast majority of cases are asymptomatic [1], and where symptoms do occur, these commonly manifest with a fever, generalised pain, nausea and vomiting [2,3]. Severity of infection has been traditionally assessed by cardiovascular compromise, but most recently is the addition of central nervous system (CNS) involvement as a factor of severity since the number of cases describing dengue neurotropism have come to light $[2,3]$. This may be because factors contributing to neurological manifestations are themselves of increased severity of disease, for example prolonged shock, hepatic failure and hyponatraemia [4-6].

Damage to the spinal cord (myelitis) following infection can occur during infection (parainfectious) via direct invasion, or after infection (postinfectious) via a proposed immune-mediated inflammatory process $[3,7,8]$. Transverse myelitis has been described in a number of case reports where the main manifestations are sensorimotor disturbance of the lower limbs and urinary retention [7,9-15]. Currently the mechanisms of spinal cord damage in dengue are poorly defined and the exact burden of these neurological manifestations is yet to be fully assessed. Hence, we summarised the literature on the risks of transverse myelitis following dengue infection as well as the proposed mechanisms behind this.

\section{Methods}

\subsection{Data Search and Selection}

A search was designed to identify case reports and observational studies (case series, cohort study, case-control study) reporting transverse myelitis as a complication of dengue viral infection. It aimed to include all publications that evaluated the current data in use of the risk of transverse myelitis (TM) following dengue virus infection globally. We searched MEDLINE, ISI web of knowledge, conference proceedings and EMBASE from 1 January 1974 to 26 December 2017. Both free text and the use of medical subheadings (MeSH) terms were used as search items. An initial search was conducted in order to scope all appropriate search terms followed by a more extensive search using two similar search criteria. The MeSH terms and free text terms used are included in the Appendix A.

Studies were excluded if they were individual opinion or non-availability of full text, experimental or laboratory studies or not original research. We only included studies published in English language in our review. After the initial screening process, all publications were assessed for eligibility based on their titles followed by abstracts and full text.

\subsection{Study Selection}

Studies were eligible for inclusion if they reported neurological complications following dengue infection which were relevant to our study focus; to review the risk of TM following dengue infection. Articles irrelevant to the study were excluded or if they didn't mention the risk of TM in relation to dengue infection.

Two reviewers (G.O. and N.B.) independently screened the titles and abstracts of papers identified by the electronic searches, evaluating exclusion and inclusion criteria for all papers. We retrieved full text articles of included publications and each was then independently reviewed for eligibility.

\subsection{Quality Assessment and Data Extraction}

Two independent reviewers (G.O. and N.B.) reviewed the methodological quality of included studies, the comparability of case and controls, and outcomes. The explanatory variables extracted included: country, study design, description of study subjects, underlying comorbidity, clinical presentation, management and the outcome of the patient with TM. The study quality assessment was undertaken using the Reporting Items for Systematic Reviews and Meta-analyses (PRISMA) statement for the conduct and reporting of systematic reviews [16]. 


\subsection{Data Analysis}

Eligible studies were summarised using descriptive analyses to provide the overview of the information on populations studied, clinical presentations, underlying comorbidity and patient mortality outcomes. We calculated the age and sex distribution of TM generalised from the extracted data. We also calculated the risk of TM following dengue infection in children following dengue infection and compared this with that obtained in the adults for the outcome of interest where data were available. We calculated the crude fatality rate as the total number of mortality following TM divided by total number of reported TM cases over the same period. Eligible studies were then analysed qualitatively using Microsoft Office Excel 2007 and summarised.

\section{Results}

We identified 242 potential studies, of which 62 were duplicates. A further 136 were excluded on the basis of title and abstract and 19 studies did not meet the eligibility criteria on full text screening (Figure 1). The remaining 25 studies were eligible and full text was assessed for inclusion in the final review $[7,9,10,12-15,17-34]$. Most of the studies were from Asia $(76 \% ; 19 / 25)$ and the rest from South America $(24 \% ; 6 / 25)$. The majority of the studies were case reports $(64 \% ; 16 / 25)$, case series $(8 \% ; 2 / 25)$, cohort study $(16 \% ; 4 / 25)$, cross-sectional studies $(8 \% ; 2 / 25)$ and one prospective study $(4 \% ; 1 / 25)$. Only five studies reported dengue serotype; three studies had serotype 1 only, serotype 2 only, and serotype 3 only. The other two studies displayed had either dengue serotypes 1-3, or all four serotypes. A summary of the study design, study subjects, data collection method, and treatment is presented in Tables 1 and 2. Most of the included studies did not report the ethnicity.
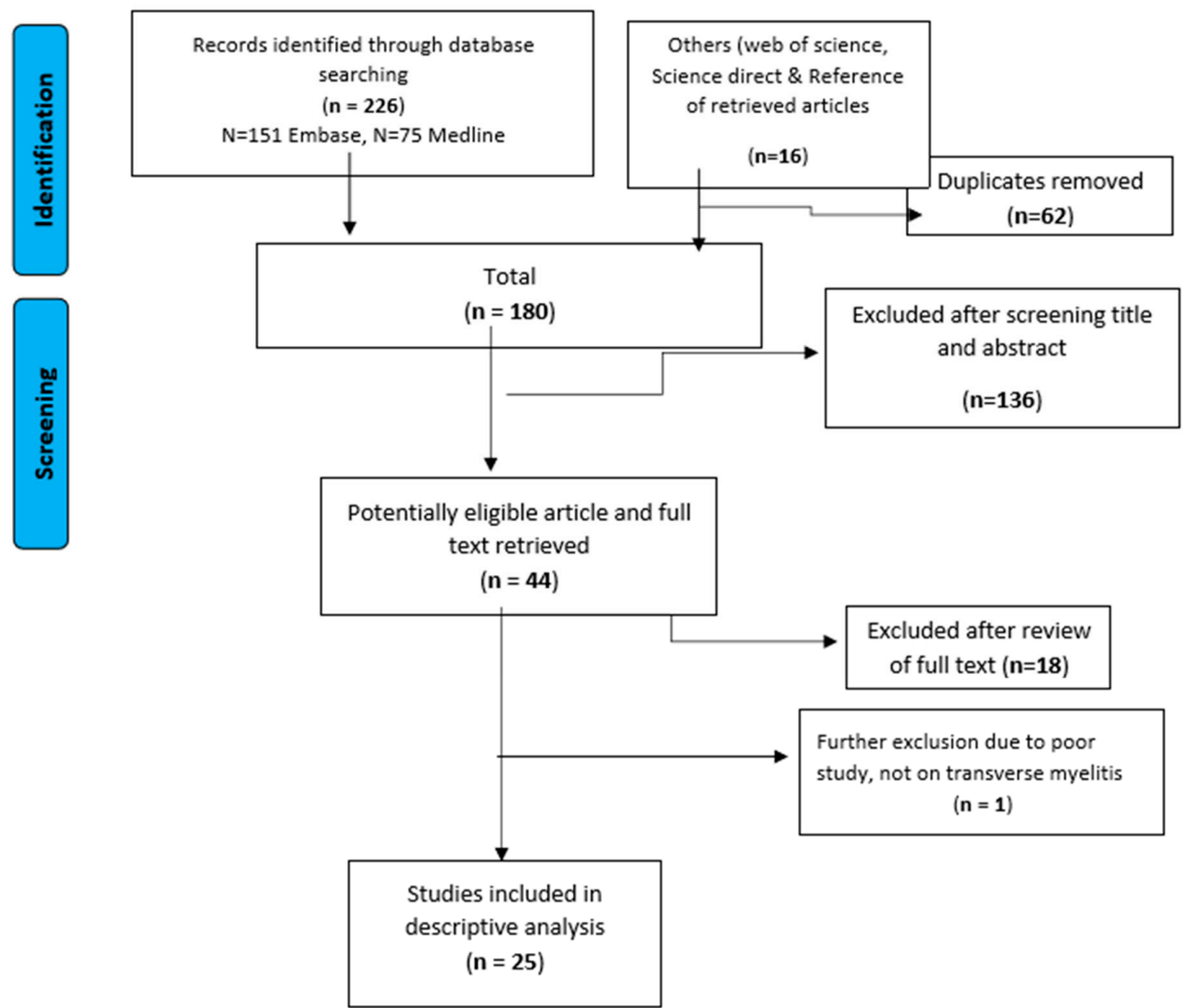

Figure 1. Identification and the selection of eligible studies in the systematic review. 
Table 1. Description of the study design and the reported outcomes.

\begin{tabular}{|c|c|c|c|c|c|c|}
\hline Study & Year of Study & Country & Study Design & Number of Dengue Cases & Diagnosis Method & Outcome \\
\hline Singh et al. [17] & 2013 & India & Case Report & 1 & Dengue IgM seropositivity & 1 patient died. \\
\hline Ghosh et al. [18] & 2011 & India & Case Report & 1 & Dengue IgM seropositivity CSF analysis & full recovery \\
\hline Seet et al. [7] & 2006 & Singapore & Case Report & 1 & Antibody index ratio of dengue IgM:IgG & full recovery \\
\hline Kunishige et al. [13] & 2004 & Singapore & Case Report & 1 & Dengue IgM seropositivity (CSF) & partial recovery \\
\hline Fong CY et al. [19] & 2016 & Malaysia & Case Report & 1 & Dengue IgM seropositivity & full recovery \\
\hline Gupta et al. [20] & 2013 & India & Case report & 1 & $\begin{array}{c}\text { Dengue IgM seropositivity (ELISA) } \\
\text { History } \\
\text { NS1 ag assay }\end{array}$ & full recovery \\
\hline Wasay et al. [21] & 2008 & Pakistan & Case Series & 6 & Dengue IgM seropositivity & 4 patients made a full recovery, 2 patients died. \\
\hline Samanta et al. [22] & 2012 & India & Case Series & 3 & Dengue IgM seropositivity (serum/viral/blood) & $\begin{array}{l}1 \text { patient made a full recovery, } 1 \text { patient made a } \\
\text { partial recovery, } 1 \text { patient died. }\end{array}$ \\
\hline Misra et al. [23] & 2015 & India & Case Study & 116 & $\begin{array}{l}\text { Dengue IgM seropositivity } \\
\text { History, Exam, NS1 antigen assay }\end{array}$ & $\begin{array}{l}78 \text { patients made a full recovery, } 27 \text { patients } \\
\text { made a partial recovery, } 11 \text { patients died. }\end{array}$ \\
\hline Sahu et al. [24] & 2014 & India & Cohort & 484 & Dengue IgM seropositivity & $\begin{array}{l}479 \text { patients made a full recovery, } \\
5 \text { patients died }\end{array}$ \\
\hline Soars et al. [25] & 2006 & Brazil & Cross-sectional study & 13 & Dengue IgM seropositivity (blood/CSF (ELISA)) & $\begin{array}{c}12 \text { patients made a full recovery, } 1 \text { patient with } \\
\text { encephalitis died }\end{array}$ \\
\hline Weeratunga et al. [26] & 2014 & Sri Lanka & Cross-sectional Study & 7 & Dengue IgM seropositivity (blood/CSF) & $\begin{array}{l}6 \text { patients made a full recovery, } 1 \text { patient made a } \\
\text { partial recovery. }\end{array}$ \\
\hline Puccioni-Sohler et al. (Brazil) [12] & 2009 & Brazil & Retrospective study & 27 & Dengue IgM seropositivity & Partial recovery \\
\hline Larik et al. [10] & 2012 & Singapore & Case Report & 1 & Dengue IgM seropositivity Dengue RNA & Full recovery \\
\hline Lim et al. [27] & 2012 & Singapore & Case Report & 1 & Dengue IgM seropositivity & Partial recovery \\
\hline Tomar et al. [28] & 2015 & India & Case Report & 1 & Dengue IgM seropositivity & Full recovery \\
\hline Mo et al. [29] & 2016 & China & Case Report & 1 & Dengue IgM/IgG seropositivity (CSF) & Partial recovery \\
\hline Mota et al. [30] & 2017 & Brazil & Case Report & 1 & Dengue IgM seropositivity & Partial recovery \\
\hline Leão et al. [14] & 2000 & Brazil & Case Report & 1 & Dengue IgM seropositivity (CSF) & Full recovery \\
\hline Miranda de Sousa A et al. [31] & 2014 & Brazil & Case Report & 1 & Dengue IgM seropositivity (CSF) & Full recovery \\
\hline Renganathan et al. [32] & 1996 & Malaysia & Case Report & 1 & Dengue IgM seropositivity & Full recovery \\
\hline Chanthamat et al. [15] & 2010 & Thailand & Case Report & 1 & NA & Full recovery \\
\hline Solomon et al. [33] & 2000 & Vietnam & Prospective Study & 1675 & IgM/IgG seropositivity (CSF) & Partial recovery \\
\hline Sousa et al. [9] & 2004 & Brazil & Retrospective Study & 51 & Dengue IgM seropositivity (CSF) & $\begin{array}{l}49 \text { patients made a full recovery, } 2 \text { patients had } \\
\text { partial recovery }\end{array}$ \\
\hline Verma et al. [34] & 2011 & India & Retrospective Study & 26 & Dengue IgM seropositivity & Partial recovery \\
\hline
\end{tabular}

Note: Abbreviations: IV: intravenous; IgM: immunoglobulin M; IgG: immunoglobulin G; NA: not available; CSF: cerebrospinal fluid; ELISA: enzyme-linked immunosorbent assay; RNA: ribonucleic acid electroencephalogram; NS1: nonstructural protein 1; WHO: World Health Organisation. Definitions. Full recovery: none or slight disability, Partial recovery: moderate or severe disability (may need help walking, numbness, tingling, may need ongoing assistance with daily activities). 
Table 2. Characteristics of published studies included in the systematic review.

\begin{tabular}{|c|c|c|c|c|c|}
\hline Study & Age & Sex & Number of TM Cases & Serotype & Treatment \\
\hline Singh et al. [17] & 45 & Male & 1 & - & $\begin{array}{c}\text { T9-11 laminectomy } \\
\text { Evacuation of epidural haematoma. } \\
\text { Multiple blood and platelet transfusions. Conservative } \\
\text { management applied. }\end{array}$ \\
\hline Ghosh et al. [18] & 4 & & 1 & - & $\begin{array}{l}\text { High dose methylprednisolone. } \\
\text { Platelet transfusion and Packed red cell Supportive therapy for } \\
\text { hepatitis and glomerulonephritis }\end{array}$ \\
\hline Seet et al. [7] & 44 & Female & 1 & - & $\begin{array}{l}\text { IV methylprednisolone } 1 \mathrm{~g} \text { for } 5 \text { days, } \\
\text { Spinal MRI, } \\
\text { Catheterisation for urinary retention, } \\
\text { Intensive physiotherapy }\end{array}$ \\
\hline Kunishige et al. [13] & 42 & Male & 1 & 1 & $\begin{array}{l}\text { IV methylprednisolone } \\
\text { Antibiotics }\end{array}$ \\
\hline Fong CY et al. [19] & 12 & Female & 1 & - & $\begin{array}{c}\text { IV methylprednisolone } 30 \mathrm{mg} / \mathrm{kg} / \text { day for } 3 \text { days followed by } \\
\text { oral prednisolone } \\
\text { IV Immunoglobulin (IVIG) } 1 \mathrm{~g} / \mathrm{kg} / \text { day for } 2 \text { days. } \\
\text { Intubated, } \\
6 \text { cycles of plasma exchange. } \\
\text { Cervical epidural haematoma was managed conservatively }\end{array}$ \\
\hline Gupta et al. [20] & 26 & Female & 1 & - & $\begin{array}{l}\text { Methylprednisolone } 1.0 \mathrm{mg} / 5 \text { days Mechanical ventilation for } \\
2 \text { weeks }\end{array}$ \\
\hline Wasay et al. [21] & $18-35$ & 5 females, 1 male & 1 & - & MRI/CT +/- EEG observations \\
\hline Samanta et al. [22] & & Male & 1 & $\begin{array}{l}\text { primary/ secondary } \\
\text { infection }\end{array}$ & $\begin{array}{l}\text { Pulsed methylprednisolone } \\
\text { Conservative therapy }\end{array}$ \\
\hline Misra et al. [23] & $5-70$. & 26 females, 90 males & 1 & 1,2 and 3 & - \\
\hline Sahu et al. [24] & $25+/-18.3$ & & 7 & - & Symptomatic treatment \\
\hline Soars et al. [25] & $11-79$. & 10 female, 3 male & 2 & 1,2 and 3 & $\begin{array}{l}\text { Corticosteroids } \\
\text { IVIG }\end{array}$ \\
\hline Weeratunga et al. [26] & Mean: 35 & 1 female, 6 male & 2 & - & Methylprednisolone pulsed $1 \mathrm{~g} / 3$ days \\
\hline Puccioni-Sohler et al. (Brazil) [12] & $22-74$ & 6 females, 4 males & 3 & - & $\begin{array}{l}\text { Methylprednisolone } 1.0 \mathrm{mg} / 5 \text { days. Additional Human IVIG } \\
400 \mathrm{mg} / \mathrm{kg} / 5 \text { days for } 1 \text { patient }\end{array}$ \\
\hline Larik et al. [10] & 43 & Male & 1 & - & IVIG \\
\hline Lim et al. [27] & 43 & Male & 1 & - & IVIG \\
\hline Tomar et al. [28] & 42 & Male & 1 & - & IV Methylprednisolone \\
\hline
\end{tabular}


Table 2. Cont.

\begin{tabular}{|c|c|c|c|c|c|}
\hline Study & Age & Sex & Number of TM Cases & Serotype & Treatment \\
\hline Mo et al. [29] & 65 & Male & 1 & - & $\begin{array}{l}\text { IV Methylprednisolone } \\
\text { IVIG } \\
\text { Plasma Exchange }\end{array}$ \\
\hline Mota et al. [30] & 21 & Male & 1 & - & IV Methylprednisolone \\
\hline Leão et al. [14] & 58 & Male & 1 & - & Ceftriaxone \\
\hline Miranda de Sousa A et al. [31] & 11 & Female & 1 & - & IV Methylprednisolone $1 \mathrm{~g} /$ day followed by prednisolone \\
\hline Renganathan et al. [32] & 14 & Female & 1 & - & Symptomatic treatment \\
\hline Chanthamat et al. [15] & 61 & Female & 1 & - & IV Methylprednisolone \\
\hline Solomon et al. [33] & & & 2 & - & Symptomatic treatment \\
\hline Sousa et al. [9] & Mean:34 & & 26 & 3 & IV methylprednisolone for 5 days \\
\hline Verma et al. [34] & & 8 females, 18 males & 1 & - & IV Methylprednisolone \\
\hline
\end{tabular}

electroencephalogram; T9-11: thoracic vertebra 9 to 11 ; kg: kilogram. 
A total 2672 cases of Dengue fever in all ages involving 289 (10.8\%; (289/2672)) with neurological complications in 25 studies were included in the final analysis (Table 2).

Overall 2.3\% (61/2672) had TM, and children (<18 years old) constituted 13\% (8/61) of TM cases reported by six studies. Twenty-two studies reported epidemiological data; the neurological complication was twice in males compared to female $67.7 \%(130 / 192)$ vs. $32.7 \%(62 / 192)$ and 1.5 -fold increase TM for males $59.3 \%(32 / 54)$ vs. $40.7 \%(22 / 54)$. The mean age at presentation was 33.1years (range: $0.75-61$ ). Of the 19 papers reporting the onset of DF to the time it was complicated by TM, the average was 11.7 days (range: $5-42$ ).

All the studies reported method of diagnosing TM, and apart from the use of radiological investigation by all the studies, the method of diagnosing TM due to DF was mainly IgM seropositivity $(92 \%(n=23 / 25))$. In addition, 12 papers mentioned additional methods were also used in diagnosing cases of TM; cerebrospinal fluid analysis (CSF) analysis (nine studies), IgG antibodies (two studies), clinical features and nonstructural protein 1 (NS1) antigen assay (two studies) with one other study which used an antibody index ratio of IgM to IgG.

Out of the 25 studies, 92\% $(n=23 / 25)$ specified their management plans. High dose methylprednisolone was used in $82.6 \%(n=19 / 23)$ of studies with additional antibiotic cover. Twenty-two per cent $(n=5 / 23)$ of studies required in addition intravenous immunoglobulins, of which two had assisted ventilation and one had blood/platelet transfusions. Three studies employed a symptomatic management plan. Only one study treated with antibiotics only and a laminectomy was a modality of management in one of the studies.

The commonest treatment modality was steroids $82.6 \%(n=19 / 23)$. In terms of recovery after, only half had full recovery $50.8 \%(\mathrm{n}=31 / 61)$ from TM. There was no mortality following dengue infection reported, however, the crude case fatality rate following TM was $3.3 \%(n=2 / 61)$, involving a 45-year-old male and a 9-month-old male infant.

\section{Discussion}

A detailed systematic review of the literature identified all reported cases of TM following DF in endemic countries irrespective of the mode of presentation. Overall there were 61 cases in the literature, accounting for $2.3 \%$ of DF and the crude case-fatality rate among TM cases was very low at $3.3 \%$. These findings, contrary to previously reported rare occurrence, confirm the prevalence of TM following Dengue. Moreover, Dengue is the most common arboviral disease [35], and occurs in Southeast Asia, East and West Africa, the Caribbean and the Americas [36]. Interestingly, the majority of TM cases were in Asia and a few reported cases in North America. One of the explanations for the low prevalence of TM following DF in West Africa and the Caribbean is that the Asian population appears to be prone to autoimmune injury of the spinal cord and some genetic make-up, including the type of Dengue that causes TM might be different and their contributing factors. Although, neurological complications in dengue fever have been documented with all serotypes, we also observed that it is more common with serotypes 2 and 3 [33].

For example, of the four strains of dengue virus implicated in the disease, DEN3, DEN2 and DEN1 are the prominent serotypes in India. The DEN2 has been reported in more than $75 \%$ of the cases in breakouts since 2010 [37,38]. A similar finding was observed in the review with serotype 2 having been the most commonly isolated, however, this was only reported in five of the studies.

The mechanisms of viral transmission and spinal cord injury induced by dengue virus are unclear. Two mechanisms have been postulated: by direct invasion of the cord and by active replication within the spinal cord [13], which is common during the early phase or postinfectious immune injury [39]. Since only five studies were able to isolate dengue IgG/IgM or antigen in the CSF, it is therefore most likely that both mechanisms have been implicated in the cases in this review.

One important finding is the 2-fold increase in neurological complication, and a 1.5-fold increase in those that had TM in females compared to males. In addition, the two mortalities were in males. This supports the earlier studies indicating that other factors including biology, environment and 
experience are contributors to human health [40], but contrary to the reports that most autoimmune diseases are more frequent in females than in males [41].

There is currently no agreed consensus on the management of TM. Our findings showed that almost $80 \%$ cases were treated with high dose of methylprednisolone despite insufficient evidence regarding the utility of steroids in treating transverse myelitis [42]. It is therefore advisable that until more robust evidence is available, administration of high dose intravenous (IV) methylprednisolone will be the first treatment of choice in TM to enhance neurological functions. Few cases however required immunoglobulins but this was introduced at a later stage, and to those cases that are presumed to be very sick, thus assessing the efficacy at this stage becomes difficult. This has been considered mainly as second line therapy in patients who have not recovered or are poorly recovering from TM [42].

Due to the supposedly rarity of TM associated DF, there has been controversy as to the actual prevalence of TM following DF. de Sousa AM [9] and colleagues in a retrospective study conducted in the Brazilian Amazon region showed almost half of all DF cases had TM following DF (44\%, 26/59). This was adduced to an epidemic of DF at the time of the study compared to the study in a tertiary centre in India where of the 116 patients with DF only $1 \%$ had TM. Our review of $2.3 \%$ of TM-associated DF may have been underestimated and should therefore be interpreted with caution, since some post infectious TM have been known to present even months after the primary DF infection [23,31]. More importantly, is the significant morbidity associated with TM following DF, as only half had a full recovery from TM before discharge with $19.7 \%$ with no reported recovery. This highlights the need for a careful evaluation of patients with DF for TM and other possible neurological complications, and prompt management as high dose steroids has shown to be effective, especially if instituted early in the management of suspected cases of TM following Dengue.

However, our results demonstrate the strengths of combining outcomes of rare events through a detailed systematic review of the literature. The large number of case reports and lack of observational studies was a limitation; consequently, we were unable to conduct any meta-analyses to compare differences in other TM-associated neurological complications or calculate risks associated with clinical outcomes. In addition, as would be expected from case reports, several of the population denominators were not available to identify cases; this could potentially lead to double counting of the same cases. Therefore, it is important that future studies report the number of cases of DF during the time period so that TM rate can be calculated and compared in different population.

\section{Conclusions}

This review highlights the risk of TM following dengue. Although neurological complications are rare, especially TM, once set in, they are associated with significant morbidity. A high index of suspicion is therefore required with careful evaluation and follow-up of patients, as well as, prompt management to enhance recovery.

Author Contributions: N.B. reviewed the literature, analysed the data, was involved in the interpretation of the data, writing the report (including the first draft), coordinated the production of the manuscript, had full access to all the data in the study, takes responsibility for the integrity and accuracy of the data analysis and approved the final manuscript as submitted. D.A. and O.O. carried out the initial analyses, were involved in the interpretation of the data and writing of the report and approved the final manuscript as submitted. G.O. conceptualised and designed the study, was involved in the interpretation of the data and writing the report, coordinated the production of the manuscript, had full access to all the data in the study, takes responsibility for the integrity and the accuracy of the data analysis and approved the final manuscript as submitted. All authors approved the final manuscript submitted and also agreed to be responsible for all aspects of the work.

Funding: No external funding was received for the design, conduct of the study, collection, management, analysis, and interpretation of the data; preparation, review or approval of the manuscript; and decision to submit the manuscript for publication.

Conflicts of Interest: The authors declare no conflicts of interest. 


\section{Appendix A}

Table A1. FreeText and MeSH search terms.

\begin{tabular}{cc}
\hline Category & Search Terms \\
\hline Transverse Myelitis & "transverse myelitis" or "myelitis" or "TM" or "*Myelitis, Transverse/" \\
\hline Dengue Virus & "DEN" or "DHF" or "*Severe Dengue/" or "*Dengue Virus/* \\
\hline
\end{tabular}

Table A2. FreeText and MeSH search terms results.

\begin{tabular}{cc}
\hline Search & Results \\
\hline Transverse Myelitis Category & 146,970 \\
\hline Dengue Virus Category & 83,794 \\
\hline Transverse Myelitis AND Dengue Virus Category (ENG) & 226 \\
\hline (Additional publications from contacts) & 16 \\
\hline Duplicates Removal (62) & 180 \\
\hline Limits Applied and Studies Removed (136) & 44 \\
\hline Title and Abstract Exclusion (18) & 26 \\
\hline Full Text Exclusion (1) & 25 \\
\hline
\end{tabular}

\section{References}

1. Bhatt, S.; Gething, P.W.; Brady, O.J.; Messina, J.P.; Farlow, A.W.; Moyes, C.L.; Drake, J.M.; Brownstein, J.S.; Hoen, A.G.; Sankoh, O.; et al. The global distribution and burden of dengue. Nature 2013, 496, 504-507. [CrossRef] [PubMed]

2. World Health Organisation. Dengue Guidelines for Diagnosis, Treatment, Prevention and Control Treatment, Prevention and Control Treatment, Prevention and Control. 2009. Available online: http://www.who.int/ tdr/publications/documents/dengue-diagnosis.pdf (accessed on 26 April 2018).

3. Carod-Artal, F.J.; Wichmann, O.; Farrar, J.; Gascón, J. Neurological complications of dengue virus infection. Lancet Neurol. 2013, 12, 906-919. [CrossRef]

4. Hendarto, S.K.; Hadinegoro, S.R. Dengue encephalopathy. Acta Paediatr. Jpn. 1992, 34, 50-57. [CrossRef]

5. Kho, L.K.; Sumarmo; Wulur, H.; Jahja, E.C.; Gubler, D.J. Dengue hemorrhagic fever accompanied by encephalopathy in Jakarta. Southeast Asian J. Trop. Med. Public Health 1981, 12, 83-86. [PubMed]

6. Nimmannitya, S.; Thisyakorn, U.; Hemsrichart, V. Dengue haemorrhagic fever with unusual manifestations. Southeast Asian J. Trop. Med. Public Health 1987, 18, 398-406.

7. Seet, R.C.S.; Lim, E.C.H.; Wilder-Smith, E.P.V. Acute transverse myelitis following dengue virus infection. J. Clin. Virol. 2006, 35, 310-312. [CrossRef]

8. Li, G.H.; Ning, Z.J.; Liu, Y.M.; Li, X.H. Neurological Manifestations of Dengue Infection. Front. Cell Infect. Microbioogyl. 2017, 7, 449. [CrossRef]

9. De Sousa, A.M.; Alvarenga, M.P.; Alvarenga, R.M.P. A cluster of transverse myelitis following dengue virus infection in the brazilian Amazon region. Trop. Med. Health 2014, 42, 115-120. [CrossRef]

10. Larik, A.; Chiong, Y.; Lee, L.C.; Ng, Y.S. Longitudinally extensive transverse myelitis associated with dengue fever. BMJ Case Rep. 2012, 2012, bcr1220115378. [CrossRef]

11. Singh, P.; Joseph, B. Paraplegia in a patient with dengue. Neurol. India 2010, 58, 962. [CrossRef]

12. Puccioni-Sohler, M.; Soares, C.N.; Papaiz-Alvarenga, R.; Castro, M.J.C.; Faria, L.C.; Peralta, J.M. Neurologic dengue manifestations associated with intrathecal specific immune response. Neurology 2009, 73, 1413-1417. [CrossRef]

13. Kunishige, M.; Mitsui, T.; Tan, B.H.; Leong, H.N.; Takasaki, T.; Kurane, I.; Mihara, A.; Matsumoto, T. Preferential gray matter involvement in dengue myelitis. Neurology 2004, 63, 1980-1981. [CrossRef] [PubMed] 
14. Leão, R.N.; Oikawa, T.; Rosa, E.S.; Yamaki, J.T.; Rodrigues, S.G.; Vasconcelos, H.B.; Sousa, M.R.; Tsukimata, J.K.; Azevedo, R.S.; Vasconcelos, P.F. Isolation of dengue 2 virus from a patient with central nervous system involvement (transverse myelitis). Rev. Soc. Bras. Med. Trop. 2002, 35, 401-404. [CrossRef] [PubMed]

15. Chanthamat, N.; Sathirapanya, P. Acute transverse myelitis associated with dengue viral infection. J. Spinal Cord. Med. 2010, 33, 425-427. [CrossRef]

16. PRISMA. The PRISMA Statement. Available online: http://www.prisma-statement.org/statement.htm (accessed on 1 October 2018).

17. Singh, M. Spinal epidural hematoma with myelitis and brainstem hemorrhage: An unusual complication of dengue fever. Neurol. India 2013, 61, 541-543. [CrossRef] [PubMed]

18. Ghosh, M. Dengue infection with multi-organ involvement. Scand. J. Infect. Dis. 2011, 43, 316-318. [CrossRef]

19. Fong, C.Y. Longitudinal extensive transverse myelitis with cervical epidural haematoma following dengue virus infection. Eur. J. Paediatr. Neurol. 2016, 20, 449-453. [CrossRef]

20. Gupta, M. Acute disseminated encephalomyelitis associated with dengue infection: A case report with literature review. J. Neurol. Sci. 2013, 335, 216-218. [CrossRef]

21. Wasay, M. Encephalitis and myelitis associated with dengue viral infection clinical and neuroimaging features. Clin. Neurol. Neurosurg. 2008, 110, 635-640. [CrossRef]

22. Samanta, M. Unique neurological manifestations of dengue virus in pediatric population: A case series. J. Trop. Pediatr. 2012, 58, 398-401. [CrossRef]

23. Misra, U.K.; Kalita, J.; Mani, V.E.; Chauhan, P.S.; Kumar, P. Central nervous system and muscle involvement in dengue patients: A study from a tertiary care center. J. Clin. Virol. 2015, 72, 146-151. [CrossRef] [PubMed]

24. Sahu, R. Neurologic complications in dengue virus infection: A prospective cohort study. Neurology 2014, 83, 1601-1609. [CrossRef] [PubMed]

25. Soares, C.N. Dengue infection: Neurological manifestations and cerebrospinal fluid (CSF) analysis. J. Neurol. Sci. 2006, 249, 19-24. [CrossRef] [PubMed]

26. Weeratunga, P.N. Neurological manifestations of dengue: A cross sectional study. Travel Med. Infect. Dis. 2014, 12, 189-193. [CrossRef] [PubMed]

27. Lim, E.W.; Divakar, G.T.; Lo, Y.L.; Yip, C.W. Poster session 2, Monday 10 September. Eur. J. Neurol. 2012, 19, 648.

28. Tomar, L.R.; Mannar, V.; Pruthi, S.; Aggarwal, A. An Unusual Presentation of Dengue Fever: Association with Longitudinal Extensive Transverse Myelitis. Permanente J. 2015, 19, 133.

29. Mo, Z.; Dong, Y.; Chen, X.; Yao, H.; Zhang, B. Acute transverse myelitis and subacute thyroiditis associated with dengue viral infection: A case report and literature review. Exp. Ther. Med. 2016, 12, 2331-2335. [CrossRef]

30. De Oliveira Mota, M.T.; Estofolete, C.F.; Zini, N.; Terzian, A.C.; Gongora, D.V.; Maia, I.L.; Nogueira, M.L. Transverse Myelitis as an Unusual Complication of Dengue Fever. Am. J. Trop. Med. Hyg. 2017, 96, 380-381. [CrossRef]

31. De Sousa, A.M.; Puccioni-Sohler, M.; Alvarenga, M.P.; Alvarenga, R.M.; Borges, A.D.; Adorno, L.F. Post-dengue neuromyelitis optica: Case report of a Japanese-descendent Brazilian child. J. Infect. Chemother. 2006, 12, 396-398. [CrossRef]

32. Renganathan, A.; Ng, W.K.; Tan, C.T. Transverse myelitis in association with dengue infection. Neurol. J. Southeast Asia 1996, 1, 61-63.

33. Solomon, T.; Dung, N.M.; Vaughn, D.W.; Kneen, R.; Raengsakulrach, B.; Loan, H.T.; Day, N.P.; Farrar, J.; Myint, K.S.; Warrell, M.J.; et al. Neurological manifestations of dengue infection. Lancet 2000, 353, 1053-1059. [CrossRef]

34. Verma, R.; Sharma, P.; Garg, R.K.; Atam, V.; Singh, M.K.; Mehrotra, H.S. Neurological complications of dengue fever: Experience from a tertiary center of north India. Ann. Indian Acad. Neurol. 2011, 14, $272-278$. [CrossRef] [PubMed]

35. Brady, O.J.; Gething, P.W.; Bhatt, S.; Messina, J.P.; Brownstein, J.S.; Hoen, A.G.; Moyes, C.L.; Farlow, A.W.; Scott, T.W.; Hay, S.I. Refining the global spatial limits of dengue virus transmission by evidence-based consensus. PLoS Neglected Trop. Dis. 2012, 6, e1760. [CrossRef] [PubMed]

36. Wilder-Smith, A.; Bypass, P. The elusive global burden of dengue. Lancet Infect. Dis. 2016, 16, 629-631. [CrossRef] 
37. Mishra, G.; Jain, A.; Prakash, O.; Prakash, S.; Kumar, R.; Garg, R.K.; Pandey, N.; Singh, M. Molecular characterization of dengue viruses circulating during 2009-2012 in Uttar Pradesh, India. J. Med. Virol. 2015, 87, 68-75. [CrossRef] [PubMed]

38. Afreen, N.; Deeba, F.; Naqvi, I.; Shareef, M.; Ahmed, A.; Broor, S.; Parveen, S. Molecular investigation of 2013 dengue fever outbreak from Delhi, India. PLOS Curr. Outbreaks 2014, 6. [CrossRef] [PubMed]

39. An, J.; Zhou, D.S.; Kawasaki, K.; Yasui, K. The pathogenesis of spinal cord involvement in dengue virus infection. Virch. Arch. 2003, 442, 472-481.

40. Regitz-Zagrosek, V. Sex and gender differences in health: Science \& Society Series on Sex and Science. EMBO Rep. 2012, 13, 596-603.

41. Zandman-Goddard, G.; Peeva, E.; Rozman, Z.; Ben-Zvi, I.; Langevitz, P.; Shvartser, Y.; Amital, D.; Amital, H.; Kivity, S.; Lidar, M.; et al. Sex and gender differences in autoimmune diseases. In Sex and Gender Aspects in Clinical Medicine; Springer: London, UK, 2012; pp. 101-124.

42. Lahat, E.; Pillar, G.; Ravid, S.; Barzilai, A.; Etzioni, A.; Shahar, E. Rapid recovery from transverse myelopathy in children treated with methylprednisolone. Paediatr. Neurol. 1998, 19, 279-282. [CrossRef]

(C) 2018 by the authors. Licensee MDPI, Basel, Switzerland. This article is an open access article distributed under the terms and conditions of the Creative Commons Attribution (CC BY) license (http://creativecommons.org/licenses/by/4.0/). 